\title{
Student Editorial Board for Volume 22
}

Student Editorial Board members are appointed by members of the editorial board to serve for at least one year. Student members independently review manuscripts which are also sent to their sponsoring board members. Participation on the board provides students with experience in the review process and provides authors of manuscripts with additional feedback. During the past year the following students offered generously of their time to serve the joumal as members of the Student Editorial Board. We are grateful for the contribution that each one has made to Law and Human Behavior.

Kimberly Barletto, College of Law, University of Arizona Amy Bradfield, Department of Psychology, Iowa State Universicy Angela Crossman, Department of Human Development, Cornell University Jeffrey Davis, Department of Psychiatry, University of Massachusetts Medical Center Suzanne Davis, Department of Psychology, University of Illinois-Chicago John Edens, Deparment of Law and Mental Health, University of South Florida Amy Farrell, Criminal Justice, University of Delaware

Susan Greene, Department of Psychology, University of California-Santa Cruz Amy Hackney, Department of Psychology, Saint Louis University Marianne Hallinan, Institute for Social Research, University of Michigan Beverly Hamby, Deparment of Psychology, Saint Louis University Michael Henry, Department of Psychiatry, University of Massachusetts Medical Center

Jennifer Hunt, Department of Psychology, University of Minnesota Linda Hurt, Department of Psychology, Saint Louis University

Michael Johns, Department of Psychology, University of Colorado

Karen Kadela, Department of Psychology, Saint Louis University

Antoinette Kavanaugh, Department of Psychiatry, University of Massachusetts Medical School

Michelle Keeney, Department of Clinical and Health Psychology, Allegheny University of the Health Sciences

Trudi Kirk, J.D., Ph.D. Program in Law and Psychology, Villanova University School of Law

Meredith Krause, School of Law, University of Virginia

Deborah J. Land, Department of Psychology, University of Virginia

Bradley McAuliff, Department of Psychology, Florida International University

Lisa McGuffey, Department of Psychology, University of Colorado 
Renee Melancon, Management and Policy Department, University of Arizona Maureen Outlaw, Department of Sociology, Pennsylvania State University Tony Palmer, Department of Psychiatry and Behavioral Science, Duke University Medical Center

Mark Phillips, Department of Psychology, Florida International University

Pat Pound, Department of Psychology, Saint Louis University

Joanna Pozzulo, Department of Psychology, Queens University

Shannon Rauch, Department of Psychology, Saint Louis University

Richard Redding, Department of Psychology, University of Virginia

Tracey Richmond, Department of Psychology, Claremont Grad tate University and Saint Louis University

Brenda Russell, Department of Psychology, Saint Louis University

Jason Schklar, Department of Psychology, University of Illinois-Chicago

Hope Seib, Department of Psychology, Saint Louis University

Jennifer Skeem, Department of Psychology, University of Utah

Brett Steinberg, Department of Psychology, University of South Carolina

Terri Stewart, Department of Psychology, University of Kentucky

Karen Ustad, Department of Psychiatry, University of Massachusetts Medical School

Adina Wasserman, Department of Psychology, Florida State University

Teri White, Department of Psychology, North Carolina State University

Karen Whittemore, Department of Psychology, Simon Fraser University

Amy J. Wright, Hastings College of the Law, University of California

Meagan Yarmey, Department of Psychology, York University 